\title{
The Study and Analysis of Public Opinion Crisis in Tourism Network in the "Popular Microphone Era"
}

\author{
Hui Wang \\ Jiangsu Vocational Institute of Commerce Nanjing 210000, China
}

Keywords: popular microphone era; tourism; Internet public opinion; crisis

\begin{abstract}
In the age of Internet, everyone may become an information channel and may become the main body of opinions. Just as everyone has a microphone in front of them, the new term "mass microphone" is also born. The arrival of the "popular microphone era" has set new demands for tourism to respond to Internet public opinion. This paper combines the requirements of the new network era, conducts an in-depth study of the composition and content of the tourism network's public opinion, sums up the crisis faced by the tourism network, and proposes a reasonable response method.
\end{abstract}

\section{Introduction}

The arrival of the "popular microphone" era provides a suitable platform for the masses to express their freedom of speech. Netizen can upload or create news at any time, publish opinions, attitudes and emotions on hot issues or issues through the Internet, and change the formation and dissemination of traditional public opinions. way. For tourism, rumbling is the public opinion of tourists, Netizen, etc., published on the Internet and travel hot spots, and tourism crisis events. The general situation of tourist network sensation is worth studying.

\section{Tourism Network Public Opinion}

With the development of the Internet age, media formats such as Weibo, WeChat, and forums have been widely used. Internet users are increasingly inclined to express their opinions and opinions through the Internet. Internet public opinion has become a new form of public opinion. Internet public opinion affects the development of all walks of life in China. The public opinion of the tourism network as a part of it also affects the development of tourism.

\subsection{Connotation of Tourism Network}

Internet public opinion is the attitude, opinions and opinions expressed by the public and news organizations through the Internet media on hot events [1]. Tourism network sentiment is the process of commenting on hot events in the tourism industry. The tourism hot spot events cover the following three aspects: First: The events occurred in the course of tourism activities, the places of events are 
tourist attractions, tourist hotels or amusement facilities, etc., and the circumstances are related to tourists, travel agencies, tourism activities, tourism regulations, etc, Incidents involving any one of them; Second, events must have "hot spots", that is, events that can arouse the concern of the broad masses of the people. The events should have a certain influence and can trigger events discussed by Netizen. Third, the nature of the events. It can be positive or negative, it can be a major sudden event, or it can be the context of a holiday activity or the introduction of new tourism regulations. On the basis of clarifying the tourism hot spot events, the connotation of the tourism network's public sentiment is ready to appear, namely: the talks triggered by the Internet users' or media's tourism hot events, and the expression of opinions, attitudes, emotions, etc., is a branch of the Internet public opinion.

\subsection{The Composition of Tourism Network Sensation}

The public opinion of tourism network consists of subject, object, ontology and communication media. First of all, the main body of public opinion in tourism networks refers to Netizen or news media. The lyrical subject is the person or institution that expresses opinions and attitudes on hot issues. Netizen are the direct source of speech and opinions. Under the premise that the Internet is increasingly popular, the number of Netizen is gradually increasing. News media organizations will produce and disseminate online news and set media agendas. Because the news media has the characteristics of expressing opinions independently, it has become one of the main topics of online public opinion. Tourism events can be the focus of people's hot debates, and it depends to a great extent on the exposure of Internet users and news media reports and hype. Secondly, the object of the lyrical tourism network refers to the hot events that stimulate the Internet public opinion or the hot events triggered by the Internet public opinion [2]. The object is the fuse of sensation. Third, the ontology of travel network sentiment is the expression of lyricism. Netizen express attitudes or opinions in cyberspace through text, symbols, pictures, videos, links, etc. These forms naturally become the body of sensation [8]. With the development of science and technology, the form of lyrical ontology will be more diverse, and the scope of its carriers (including WeChat Weibo, blogs, forums, question and answer communities, search engines, etc.) will gradually expand.

\subsection{Standardized Management of Tourism Network Public Opinion}

Based on the characteristics of freedom of speech on the Internet platform, there will also be some malicious attacks, false reports and other illegal activities. This requires the government and tourism enterprises and other management entities to comprehensively consider the relevant measures of crisis management, public relations, network communication and information management, and use the feedback characteristics of Internet public opinion to effectively manage the content of tourism network sensational content and ensure that the tourism network is in a legitimate position. Within the scope of elimination of false information, network rumors, cyber violence and other phenomena. The regulatory agency must ensure the legality and impartiality of its own behavior, grasp the scale between the public's right to know and the right to privacy, and the boundary between information disclosure and state secrets, so that the tourism network is in a healthy and orderly development environment. Medium [7]. 


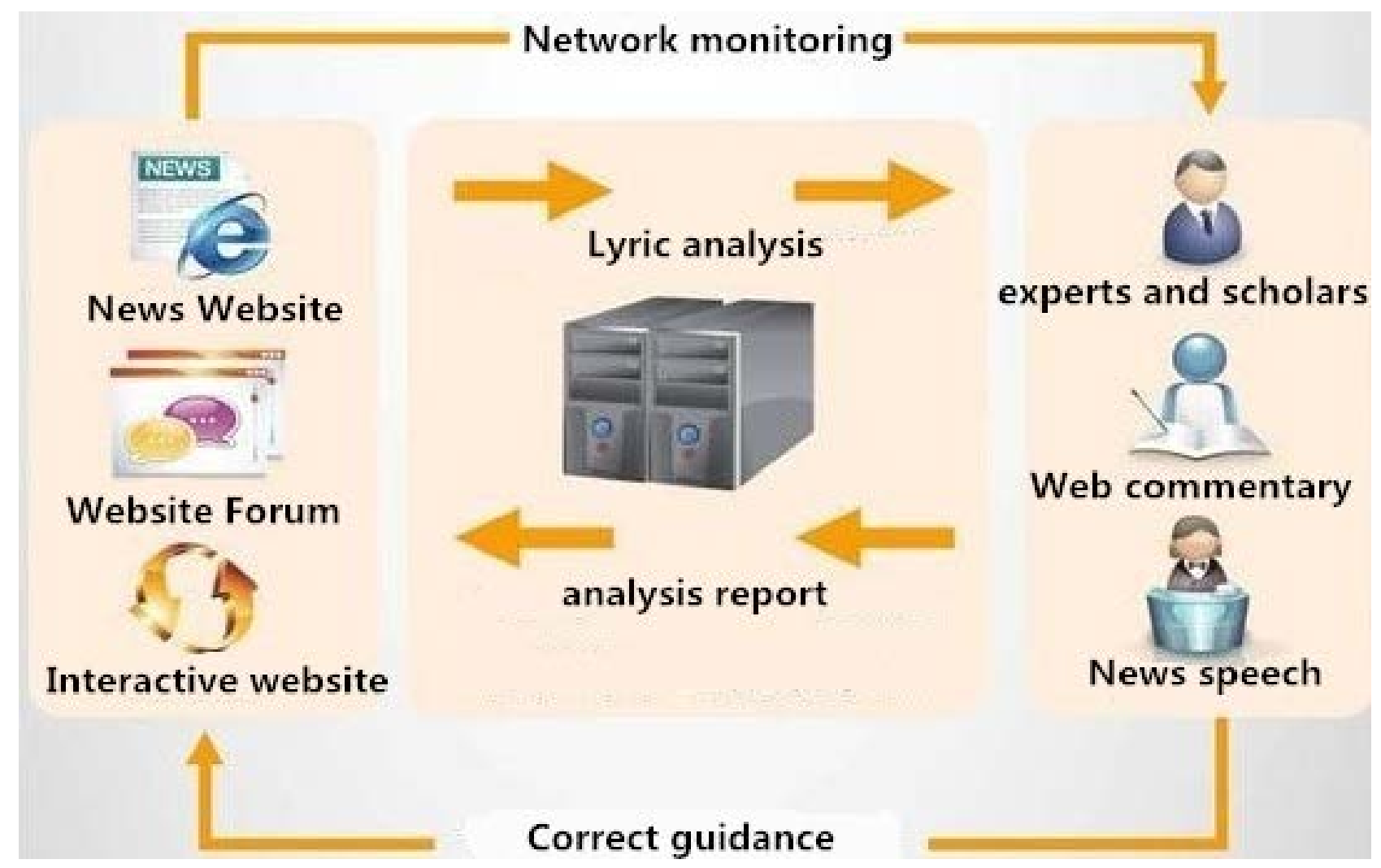

Fig. 1 Analysis of Detection and Crisis of Tourism Network Public Opinion Crisis

\section{Crisis of Tourism Network Development in "Popular Microphone" Era}

With the arrival of the "popular microphone" era, the masses' speeches have a higher influence, but the development of Internet public opinion is not entirely healthy. Combining the general situation of the tourism network in the previous article, the author analyzes the development crisis of the tourism network.

\subsection{The increasing sensational subjects with uneven development}

As the scale of Netizen grows, the "new opinion hierarchy" will follow. The "new opinion hierarchy" is different from the independent class defined by economics and sociology, but is a group divided according to the needs of different groups of people. According to the definition of Analysis and Prediction of China's Social Situation in 2009 published by the Chinese Academy of Social Sciences, the "new opinion hierarchy" refers to Netizen who are concerned about current events and are directly on the Internet.[3] With the rapid development of the Internet age, more and more people, including ordinary citizens, experts, celebrities, entrepreneurs, spokespersons, party and government cadres, etc., are happy to express their opinions through online media. They have become "new opinions". The main component. However, the development structure of these people is not balanced. According to the 38th Statistical Report on Internet Development in China Internet Information Center, as of June 2016, the proportion of young people in China's Internet users was as high as $74.7 \%$, becoming the absolute majority of Internet users. According to the occupational structure, the proportion of young and middle school students is the highest, accounting for $25.1 \%$ [4]. The psychological development of adolescents, especially middle school students, is not mature enough, social experience is limited, knowledge is kept thin, and the world outlook, outlook on life, and 
values have not yet been cultivated as a whole. The remarks made on events are subject to subjective factors, and speech lacks objectivity.

\subsection{Communicators usually taken out of context}

In order to increase the degree of attention on the Internet and to capture the amount of clicks, many message communicators are happy to intercept the most attractive parts of the tourism emergencies. The masses are attracted by the content and also have posted an impression tag on such events. This kind of sticky post-message information transmission essentially means that the incident itself is conducive to mass media. In other words, it is to create eyeballs and blogs to create a situation of public opinion. For example, the "high price shrimp" in Qingdao seafood stalls, the "best cow guide" in compulsory shopping in Yunnan, and the "first aid door" in Southern Airlines' CZ6101 all produced a tagging effect in the masses of the people. Induced travel network public opinion crisis [6].

\subsection{Poor communication between relevant subjects in tourism emergencies}

After the occurrence of tourism emergencies, there was a lack of effective communication between tourists, authorities, and tourism companies. The incident could not be solved quickly, laying a spotlight on the crisis of the tourism network. The power departments and tourism companies shirk responsibility from each other, deal with the poor performance of the incident, communicate with the outside world, and do not give tourists the opportunity to speak out and deprive the people of their right to know. Visitors can only seek help by making comments on the Internet. For example, the "price-price shrimp" incident in Qingdao was due to the fact that the relevant authorities ignored the complaints from tourists and the tourists spread information through the Internet to seek help. This made the "high price shrimp" quickly known to the nation and affected the image of Qingdao among the people.

\section{Approaches to Public Opinion Crisis of Tourism Network in the "Popular Microphone" Era}

\subsection{Avoid "one size fits all" processing}

In the event of a public sentimental crisis in the tourism network, it is necessary to avoid "one size fits all" treatment, blindly deleting information. In the era of "mass microphones", it is impractical to think through the rapid removal of information to cover up the truth. In the context of the Internet age, the speed of information transmission has already exceeded people's imagination. Only by using a fair attitude to network supervision and criticism is it. Relieve the foundation of the crisis. Do not dare to face up to the problem and try to use unrealistic sophistry to cover up the facts and deceive the behavior of Netizen. It will only intensify the conflict, and it must be believed that the eyes of the masses are brilliant. When dealing with public opinion crisis, it is necessary to pay attention to methods and methods to avoid the secondary crisis caused by improper methods and affect the reputation and credibility of the competent authorities and tourism enterprises.

\subsection{Solve problems promptly and efficiently}

In the era of "mass microphones", responding to crisis events in a timely manner and proposing reasonable solutions are the preconditions for resolving public opinion crisis. If you want to properly resolve the incident, you must earn your first spokesperson. Once there is no positive response from 
the person in charge of the relevant department for a long period of time, it will lead to negative guesses and doubts by the masses, and even cause unreasonable remarks, leading to new ones. The topic and related departments involved in the incident will fall into a vicious circle, and then they will clarify and public confidence will be greatly reduced [5]. Therefore, in order to minimize the negative impact of online public opinion, relevant responsible persons should be able to respond early this morning and take actions to achieve the same words and deeds; timely respond to social questions, and hierarchically roll out information in a rolling manner so as not to give distant opportunities for communication. At the same time, through the WeChat, Weibo, forums and other media, enhance interaction with the masses.

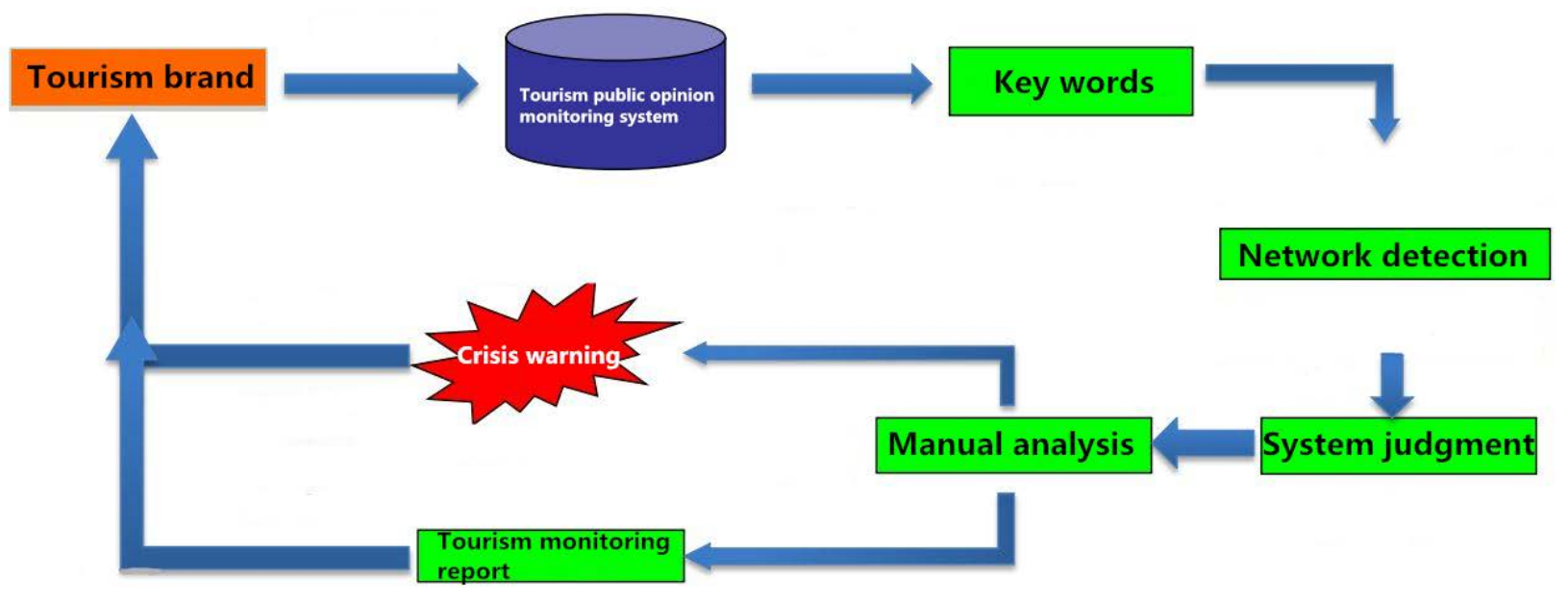

Fig. 2 Tourism crisis monitoring process

\subsection{Enhance communication with public opinion subjects}

It is essential to resolve the crisis in the tourism network and enhance communication. Crisis handlers should take the initiative to build a common platform to communicate with the participants in the public information network of the tourism network, respond positively to related issues, and guide public opinion. Second, it communicates with the media and opinion leaders to seek the authority of third-party authorities to increase the credibility of information, eliminate doubts, and resolve conflicts. Then, strengthen cooperation with the media WeChat, Weibo, and the client to build a new media camp for themselves and increase the scope of information dissemination.

\subsection{Objectively and justly solve the problem}

An objective and fair solution to the issue will help accelerate the resolution of the public opinion crisis. If the crisis management department proceed from reality and seek truth from facts, the people will naturally and willingly stop public opinion or give an objective assessment. The crisis management department must face the problem squarely, and do not evade or cover up the facts. There is no delay or no luck. Deal with the problem and take the law as the criterion, formulate detailed plans, divide the processing goals into small goals, and implement them one by one. All departments allocate clear responsibilities to avoid lazy government and idle government.

\subsection{Remedy the aftermath and reshape the public image}

After the Internet public sentiment has been dealt with, the follow-up issues of the incident should be continuously tracked, and the parties concerned should pay more attention to the aftermath of the 
relevant departments. Therefore, relevant departments must control the spread of negative comments at the time, clarify the facts and resist rumors. Guide Netizen to sensibly look at the problem, correctly guide public opinion about emotions and paranoia, and not know what to say. They are willing to take time, be willing to do practical things, and use a more comprehensive approach to reshape their public image.

\section{Conclusion}

In summary, in the era of "mass microphones", the power of public opinion based on the masses as the main body can no longer be ignored. In the process of tourism development, if the crisis of the Internet public opinion cannot be properly handled in a timely manner, it will directly affect the relevant subjective departments of tourism. The overall image of tourism enterprises and tourist attractions reduces the public credibility. Therefore, in the event of a tourism emergency, it is imperative to promptly propose a solution from the actual point of view in order to promptly increase communication with relevant personnel, minimize the degree of public opinion damage, and ensure the healthy and sustainable development of the tourism industry.

\section{Acknowledgements}

This work was supported by the General Project of Humanities and Social Sciences Research of the Ministry of Education "Study on the Network Attention Degree of Rural Tourism Destinations and the Interaction of Passenger Flows", Project Approval Number: 16YJAZH025

\section{References}

[1] Li Zhibing, et al. Study on the Dealing with the Public Opinion Crisis of Tourism Network in the "Popular Microphone" Era. Journal of Aba Teachers College, Vol. 2 (2017) No. 34, p.99-101.

[2] Sun Bo, Chen Yao, et al. Research on the Public Opinion Guidance Mechanism in the "Popular Microphone" Age. Journal of Jiangsu Vocational Technical College, Vol. 3 (2015) No. 15, p.31-35.

[3] Bai Xuefeng, et al. Discussion on the Strategy of Internet Public Opinion. News Editor, Vol. 6 (2010), p.19-20.

[4] An Jun, et al. Analysis of the Formation Process and Characteristics of Internet Public Opinion in the "Popular Microphone" Era. Journal of Tonghua Teachers College, Vol. 10 (2016), p.142-143.

[5] Lin Jingxin, Zhao Yuzhu, et al. Cybercrime crisis challenge in the era of social media. Science and Technology Think Tank, Vol. 4(2011), p.50-52.

[6] Chen Andy, et al. "Home advantage" has become an "opinion leader"-how local governments deal with Internet public opinion. Young Journalis, Vol. 8(2010), p.51-52.

[7] Wan JF, Xu YW, An SJ, et al. Analysis of the coexistence of the two public opinion fields in the "Popular Microphone Age" and the officials and the citizens. Shanghai Commercial, Vol. 11(2012), p.43-45.

[8] Li Yong, et al. Research on the Image Management of Jiangxi Government under the Network Public Opinion. Nanchang University, (2012), p.60-61. 